BIOMEDICAL AND BIOSOCIAL ANTHROPOLOGY
$\begin{gathered}\text { Official Journal of the International Academy } \\ \text { of Integrative Anthropology } \\ \text { journal homepage: http://bba-journal.com }\end{gathered}$

\title{
Stratification of the equivalent for dental treatment cost estimation among victims with maxillofacial trauma injuries occurred after road-traffic accidents
}

\author{
Plevinskis P. V. ${ }^{1}$, Mishalov V. D. ${ }^{2}$, Kozan N. M.. ${ }^{3}$, Kozlov S. V. ${ }^{4}$, Goncharuk-Khomyn M. Y. \\ ${ }^{1} \mathrm{SHEl}$ "Odessa National Medical University", Odessa, Ukraine \\ 2Shupyk National Medical Academy of Postgraduate Education, Kyiv, Ukraine \\ ${ }^{3}$ SHEI "Ivano-Frankivsk National Medical University", Ivano-Frankivsk, Ukraine \\ ${ }^{4} \mathrm{SI}$ "Dnipropetrovsk Medical Academy of the Ministry of Health of Ukraine", Dnipro, Ukraine \\ ${ }^{5}$ SHEI "Uzhhorod National University", Uzhhorod, Ukraine
}

\section{ARTICLE INFO}

Received: 27 August, 2020

Accepted: 01 October, 2020

UDC: $616-001.4 / .6-036.88-079.6$

CORRESPONDING AUTHOR

e-mail: k-sme@nmapo.edu.ua Mishalov V. D.

\begin{abstract}
The article represents the results of data analytical processing considering the equivalent for dental treatment cost estimation among victims of traffic accidents with dental and maxillofacial injuries, and analyzes the objective association level of this criterion with the parameters of the approaches used for expert assessment of maxillofacial trauma injuries. Objective of the study is to analyze the equivalent for dental treatment cost values among victims of traffic accidents with dental and maxillofacial trauma injuries, and to establish an objective level of associations of this criterion with the parameters of the approaches used for expert assessment of maxillofacial trauma injuries. The design of the work included analytical processing of data obtained from previously conducted studies of retrospective and prospective nature, related to the economic component of patients' rehabilitation due to the maxillofacial injuries occurred after road traffic accidents. The studied parameters were: the cost of treatment, duration of hospitalization, the criterion used to assess traumatic injuries of the maxillofacial region, correlation values relating trauma characteristics with the final cost of treatment and duration of hospitalization, statistical reliability of the relationships between the studied indicators of previously conducted research. Research methods: analytical, prognostic assessment, regression analysis. Current approaches used for expert severity assessment of the maxillofacial trauma injuries occurred after road accidents characterized by limited opportunities to predict and stratify the costs associated with the necessary future dental treatment of victims, but provide a sufficient level of objectification of functional and structural disorders. The increase of the expert severity assessment criteria of maxillofacial trauma injuries, in particular FISS and MFISS scores, is associated with an increase in the cost of appropriate comprehensive treatment and the potentially required duration of hospitalization, but these associations are characterized by uneven patterns of statistical dependences, and an increase in FISS and MFISS indicators beyond certain limit levels provokes a sharp advance in the cost of treatment due to the need for a longer hospitalization of the patient.

Keywords: trauma injuries, dento-alveolar system, maxillofacial area, road-traffic accidents.
\end{abstract}

\section{Introduction}

Violations of functional and anatomical integrity of the structures of the dento-alveolar system, resulting from traffic accidents, are characterized by variable patterns of formation, which depend on the mechanism of action of the traumatic factor, vector and action of force, position of the victim, safety, pre-existing changes dental status and features of the biomechanical system of the maxillofacial area as a whole [2, 15, 16, 19, 21, 23, 24, 30].

Data from a systematic review of Al-Qahtani F. et al. [2] indicate that traffic accidents are the key cause of specific injuries of the maxillofacial region, confirming the results of domestic studies on the prevalence of such injuries of 
mandibular fractures and the higher incidence of lesions in males. Similar results regarding road-traffic accidents as the predominant cause of maxillofacial injuries and the higher prevalence of mandibular fractures were also reported in systematic reviews by Sadeghi $\mathrm{N}$. et al. (45.3\%) [23], as well as Jaber M. and colleagues (24.0$87.1 \%)[15]$.

According to domestic studies, the incidence of injuries of the middle face zone as a result of road accidents is statistically lower than the incidence of criminal-associated injuries and injuries in falls, but the share of such still remains quite high and was 4.0-16.0\% in 2010-2019 [17]. According to the materials of the Department of Polytrauma, the infrastructure of maxillofacial injuries was represented by its three main types - domestic, criminal and as a result of road-traffic accidents, with the share of patients with injuries received as a result of road-traffic accidents was $31.2 \%$ [9]. It should be noted that the predominant number of cases of injuries was observed in specific age categories of people of working age, health disorders or disability, among which are characterized by the corresponding negative economic consequences.

Injuries of the maxillofacial area are most often associated with lesions of the mandible and related structures, which is justified by the mobility of the mandible due to the close functional interaction of the temporomandibular joint, masticatory muscles and the corresponding ligaments [19, 21, 23, 30]. According to Khudyk A. K. [17], the prevalence of fractures with lesions of the mandible in the period 2010-2019 statistically exceeded the prevalence of those with localization in the upper jaw. Such features of dento-alveolar system injuries are related to the need to differentiate further approaches to dental rehabilitation of victims with the restoration of functionally acceptable occlusal relationships, achieving compensatory ranges among the parameters of masticatory efficiency and masticatory capacity, and the appropriate quality of life of victims.

All of the above aspects of comprehensive dental rehabilitation are associated with the appropriate amount of financial costs, the amount of which is not possible at the stage of initial assessment of the severity of injury, given the different approaches to treatment and lack of clear criteria and algorithms to quantify the levels of relationships parameters of the severity of the lesion and economic derivatives of the prognosis of future iatrogenic interventions. Restrictions on the specific amount of future financial costs associated with treatment and rehabilitation at the time of the expert assessment of maxillofacial area injuries in turn provoke inconsistencies in the assessment of the possible range of insurance indemnities or material obligations of the road-traffic accidents culprit.

The purpose of the study is to analyze the indicators of estimating the equivalent cost of dental treatment of victims of maxillofacial injuries resulting from road-traffic accidents, and to establish an objective level of associations of this criterion with the parameters of the approach used to expert assessment of maxillofacial area injuries.

\section{Materials and methods}

The design of the work provided for analytical processing of data from previous retrospective and prospective studies related to the economic component of rehabilitation of patients with injuries of the maxillofacial area, which occurred as a result of traffic accidents [6, 11, 14]. The studied parameters were: cost of treatment, duration of hospitalization, used criterion for assessing traumatic lesions of the maxillofacial region, indicators of correlation of trauma characteristics with the final cost of treatment and duration of hospitalization, statistical reliability of the relationship between the studied indicators previously conducted research.

In order to ensure the reliability of the final results of the data processing, the selection of publications for the extraction of targets, which were further subject to statistical analysis, was carried out according to the following criteria: 1) the number of the study sample - more than 100 people; 2) the presence of a detailed description of the approach used for expert assessment of injuries of the maxillofacial area; 3$)$ the presence of the calculated coefficients of dependencies between the studied parameters; 4) confirmed the statistical reliability of the registered relationships between the studied indicators in accordance with the statistical criteria described in the study design; 5) a comparative analysis of the obtained results with the data registered in previous or related studies with the argumentation of differences between them (in the presence of relevant differences); 6) publication period (search depth) - 2010-2020.

According to the available correlations between the cost of treatment and the value of the objective criterion of severity of trauma of the maxillofacial area, calculated according to the original approach, determined the ratio of "severity of injury-cost of treatment", reflecting the economic (financial) equivalent cost per unit assessment of the severity of maxillofacial area injuries, using the statistical method of regression analysis.

Statistical processing of numerical data extracted from previous studies was provided using a spreadsheet editor Microsoft Excel 2019 (Microsoft Office 2019, Microsoft) and additional utilities integrated into this software to optimize the implementation of descriptive and inductive statistics $[12,18]$.

\section{Results}

In accordance with the previously formulated inclusion criteria, a sample of 8 studies was formed, from which the relevant data concerning the economic component of treatment of patients with maxillofacial injuries resulting from traffic accidents were extracted. The results of systematization of the analyzed data are presented in table 1. 
Table 1. Results of systematization of data of economic equivalent of an estimation of cost of treatment of injuries of a maxillofacial area, as a result of road-traffic accidents.

\begin{tabular}{|c|c|c|c|c|}
\hline Research & $\begin{array}{l}\text { Evaluation } \\
\text { criterion }\end{array}$ & $\begin{array}{l}\text { Dependence on the } \\
\text { cost of treatment }\end{array}$ & $\begin{array}{l}\text { Dependence with the } \\
\text { duration of hospitalization }\end{array}$ & $\begin{array}{l}\text { Ratio of "severity of injury-cost of treatment" } \\
\text { (economic equivalent) }\end{array}$ \\
\hline Ramalingam S. (2015) [20] & MFISS & $R=0.862(p<0.01)$ & $\mathrm{R}=0.828(\mathrm{p}<0.01)$ & 1 MFISS - 988.41 INR \\
\hline Ramalingam S. (2015) [20] & FISS & $R=0.845(p<0.01)$ & $R=0.819(p<0.01)$ & 1 FISS - 3153.92 INR \\
\hline Giriyan et al. (2019) [13] & MFISS & $R=0.398(p<0.01)$ & $R=0.477(p<0.01)$ & 1 MFISS - 2690.41 INR \\
\hline Giriyan K. et al. (2019) [13] & FISS & $R=0.429(p<0.01)$ & $R=0.433(p<0.01)$ & 1 FISS - 13571.63 INR \\
\hline $\begin{array}{l}\text { Bocchialini G., Castellani A. } \\
\text { (2019) [8] }\end{array}$ & FISS & - & $\begin{array}{c}45.94 \%{ }^{*} \\
\text { (correlation index) }\end{array}$ & 1 FISS - 1.44 days of hospitalization \\
\hline Siregar D. et al. (2019) [27] & FISS & - & $\begin{array}{c}\text { FISS }>3 \text { (odds ratio } \\
14.37)(p=0.01)\end{array}$ & - \\
\hline Aita T. et al. (2018) [1] & FISS & - & $\begin{array}{c}\text { FISS }>3 \text { (odds ratio } \\
18.69)(95 \% \text { ДI) }(p=0.01)\end{array}$ & - \\
\hline Arli C. et al. (2019) [3] & ISS & - & $R=-0.616(p=0.004)$ & - \\
\hline Saperi B. et al. (2017) [26] & ISS & $p=0.007$ & $p=0.008$ & $\begin{array}{c}\text { mild severity - US } \$ 1335.23 ; \\
\text { moderate severity - US } \$ 2044.57 ; \\
\text { severe form - US } \$ 2336.66 ; \\
\text { very severe form - US } \$ 2795.64 \text { (according to } \\
\text { the appropriate range of interpretation of } \\
\text { indicators ISS) }\end{array}$ \\
\hline Suwal R. (2018) [28] & FISS & - & $R=0.464(p<0.05)$ & - \\
\hline Suwal R. (2018) [28] & MFISS & - & $R=0.415(p<0.05)$ & - \\
\hline
\end{tabular}

\section{Discussion}

During the processing of the obtained data it was established that in the scientific literature there is a lack of a unified approach to the objectification of the economic equivalent of estimating the cost of treatment of injuries of the maxillofacial area received during the road-traffic accidents. The analyzed studies also showed a shortage of data related to the stratification of costs associated with the comprehensive treatment of victims of maxillofacial area trauma; in particular, in the vast majority of publications there were no detailed indicators of the cost of hospitalization, costs associated with specific types of surgical and follow-up rehabilitation measures, costs associated with the need for appropriate pharmacological support [1, 3, 26, 28]. In addition, it was found that the average cost of inpatient treatment of patients with maxillofacial area trauma injuries resulting from traffic accidents depends on the level of economic development of the territory within which the analysis of relevant cases, and the available quality of comprehensive dental care [8, $13,20,26]$. It is worth noting that a number of publications have described the approach to partial reimbursement of treatment costs through subsidies or insurance indemnity, but the detailed mechanism for the implementation of such still remains the subject of study.

It was found that the main in terms of objectification of the severity of injuries of the maxillofacial area are the algorithms for assessing ISS (injury severity score), FISS (Facial injury severity scale) and MFISS (Maxillofacial Injury Severity Score) $[4,10,31]$. The growth of these evaluation criteria is associated with an increase in the cost of appropriate comprehensive treatment and the potentially required duration of hospitalization, but these associations are characterized by uneven patterns of statistical dependence, as shown in Table 1. In particular, it should be noted that the dependence of financial costs for treatment on FISS and MFISS criteria demonstrates the nonlinear nature of the relationship: an increase in FISS and MFISS above certain thresholds (FISS $>3$ ) provokes a sharp jump in the cost of treatment due to the need for longer hospitalization of the patient [26].

Socio-economic significance of injuries of the maxillofacial area was noted in the works of Rybachuk A. V. and others [22], who according to a retrospective analysis of the actual material of the Department of Surgical Dentistry and Maxillofacial Surgery found that the predominant proportion of these lesions was registered among people of working age, and the severity of the lesions progressed during 2010-2014, which tended to development of multiple fractures or combined injuries.

Problems with clear verification of the characteristics of dento-alveolar system injuries are associated with limitations in the objectification of such patients at the stage of emergency hospitalization of patients after road-traffic accidents, during which standard diagnostic methods are usually used. Also, radiological methods of primary diagnosis of such patients mainly provide planimetric images that are not able to fully reflect the features of the fracture with the entry, divergence or other direction of displacement of fragments relative to each other in vertical, horizontal and especially sagittal planes [29].

A number of previous studies have noted a shortage of 
phased treatment of patients with maxillofacial area traumatic lesions in Ukraine, which in particular limits the actual possibilities for analyzing the economic costs associated with both inpatient and subsequent outpatient dental treatment, as well as the corresponding need for medical care. support, functional rehabilitation and correction of complications [22].

An increase in the number of cases of road-traffic accidents-related injuries is observed in many economically developed countries, but they also have a specific tendency to reduce the incidence of criminal, domestic and industrial injuries. In developing countries and countries with economies in transition, the ratio of the number of injuries depending on their genesis, including injuries of the maxillofacial region, is the opposite of the above, but with the prevalence among the main cases of domestic, criminal and road-traffic accidents. In addition, the results of a systematic review and meta-analysis showed that road-traffic accidents are the main cause of injuries of the maxillofacial area among children and adolescents (34.0\%; $95.0 \%$ Cl, 25-44) [5]. Similar data were noted in an up-to-date systematic review and metaanalysis of the etiologies of maxillofacial trauma in children conducted by Khosousi Sani and colleagues and published in 2020 [25]. This fact needs special attention, because damage to the structures of the dento-alveolar system at an early age can provoke functional disorders in the future associated with the growth of jaw bones, tooth formation, occlusion changes, which may prognostically require repeated iatrogenic interventions after growth. and the development of skeletal elements. Accordingly, the totality of costs associated with the treatment of dento-alveolar system injuries received in childhood or adolescence should take into account the component of treatment of secondary deformities, the clinical significance of which can be assessed after objectification of pathological and iatrogenic changes in dental status.

In a systematic review of the patterns of maxillofacial injuries conducted by Bhate K. et al. [7], the Haddon matrix was detailed as a paradigm approach to injury prevention in traffic accidents. According to the principle of construction of this matrix, there are three phases: the phase before the injury, the phase of injury and the phase after injury, each of which corresponds to the characteristic measures of primary, secondary and tertiary prevention; as well as the distribution of these phases in relation to the victim, the vehicle and the impact of environmental factors (physical and social). Ensuring an appropriate level of quality of

\section{References}

[1] Aita, T. G., Stabile, C. L. P., Garbelini, C. C. D., \& Stabile, G. A. V. (2018). Can a facial injury severity scale be used to predict the need for surgical intervention and time of hospitalization?. Journal of Oral and Maxillofacial Surgery, 76(6), 1280-e1. doi: 10.1016/j.joms.2018.02.002

[2] Alqahtani, F., Bishawi, K., \& Jaber, M. (2020). Analysis of the pattern of maxillofacial injuries in Saudi Arabia: a systematic medical care and further specialized dental treatment, as well as appropriate standards of treatment specifically for patients with maxillofacial area trauma are the main measures of tertiary prevention of complications (phase after injury), which largely determine the level and quality of life of the victim. related to the victim and the influence of external factors as components of the studied model of the Haddon matrix. In turn, the study of the equivalent of estimating the cost of dental treatment of victims with injuries of the maxillofacial area, received during the roadtraffic accidents, will help optimize approaches to formulating comprehensive algorithms for rehabilitation of victims and develop a protocol for stratified compensation of economic component of treatment at the expense of insurance compensations or from calculation of obligations of the culprit of road-traffic accidents.

\section{Conclusions}

1. Current approaches to expert assessment of the severity of injuries of the maxillofacial area resulting from a road-traffic accidents are characterized by limited opportunities in relation to forecasting and stratification of costs associated with the necessary future dental treatment of victims, but provide a sufficient level of objectification of functional and structural disorders.

2. The increase in the indicators of expert assessment of the severity of maxillofacial injuries, in particular FISS and MFISS, is associated with an increase in the cost of appropriate comprehensive treatment and potentially required duration of hospitalization, but these associations are characterized by uneven patterns of statistical dependence, and an increase in FISS and MFISS above certain threshold levels provokes a sharp jump in the cost of treatment due to the need for longer hospitalization of the patient.

3. Development of a stratification algorithm for the assessment of the cost of dental treatment of victims with dento-alveolar system injuries resulting from traffic accidents remains an urgent task of modern forensic and forensic dental examination, the solution of which will contribute to the standardization of approaches to comprehensive assessment of severity damage to the health of the victim, and reviewing rehabilitation options in terms of justifying the appropriate amount of costs to achieve a specific range of compensation (taking into account aspects of insurance compensation and possible subsidies).

review. The Saudi dental journal, 32(2), 61-67. doi: 10.1016/ j.sdentj.2019.08.008

[3] Arli, C., Ozkan, M., \& Karakus, A. (2019). Incidence, etiology, and patterns of maxillofacial traumas in Syrian patients in Hatay, Turkey: A 3 year retrospective study. Ulus travma acil cerrahi derg, 25(1), 29-33. doi: 10.5505/tjtes.2018.16243

[4] Bagheri, S. C., Dierks, E. J., Kademani, D., Holmgren, E., Bell, R. 
B., Hommer, L., \& Potter, B. E. (2006). Application of a facial injury severity scale in craniomaxillofacial trauma. Journal of oral and maxillofacial surgery, 64(3), 408-414. doi: 10.1016/ j.joms.2005.11.013

[5] Barbosa, K. G. N., de Macedo Bernardino, I., d'Avila, S., e Ferreira, E. F., \& Ferreira, R. C. (2017). Systematic review and meta-analysis to determine the proportion of maxillofacial trauma resulting from different etiologies among children and adolescents. Oral and maxillofacial surgery, 21(2), 131-145. doi: 10.1007/s10006-017-0610-9

[6] Begg, C. B., \& Berlin, J. A. (1988). Publication bias: a problem in interpreting medical data. Journal of the Royal Statistical Society: Series A (Statistics in Society), 151(3), 419-445. doi: 10.2307/2982993

[7] Bhate, K., Kshirsagar, K., Kulkarni, D., \& Mitra, S. (2016). Systematic Review of Pattern of Maxillofacial Trauma in Indian Scenario. Research Journal of Pharmaceutical Biological and Chemical Sciences, 7(6), 866-873.

[8] Bocchialini, G., \& Castellani, A. (2019). Facial trauma: A retrospective study of 1262 patients. Annals of maxillofacial surgery, 9(1), 135. doi: 10.4103/ams.ams_51_19

[9] Chebotar, O. A. Anisimova, L. A. Tkachenko, V. E., \& Ventu, O. А. (2013). Інфраструктура щелепно-лицевих ушкоджень у відділенні політравми [Infrastructure of maxillofacial injuries in the polytrauma department]. Вісник стоматологіï - Bulletin of dentistry, (4), 144-145.

[10] Chen, C., Zhang, Y., An, J. G., He, Y., \& Gong, X. (2014). Comparative study of four maxillofacial trauma scoring systems and expert score. Journal of Oral and Maxillofacial Surgery, 72(11), 2212-2220. doi: 10.1016/j.joms.2014.04.035

[11] Cios, K. J., \& Moore, G. W. (2002). Uniqueness of medical data mining. Artificial intelligence in medicine, 26(1-2), 1-24. doi: 10.1016/s0933-3657(02)00049-0

[12] Elliott, A. C., Hynan, L. S., Reisch, J. S., \& Smith, J. P. (2006). Preparing data for analysis using Microsoft Excel. Journal of investigative medicine, 54(6), 334-341. doi: 10.2310/ 6650.2006 .05038

[13] Giriyan, K., Kamath, R., D'Souza, B., Kamath, S., \& Bhat, S. R. (2019). Maxillofacial injuries and its implications on economic burden in trauma victims. Medico Legal Update, 19(1), 76-81. doi: 10.5958/0974-1283.2019.00016.1

[14] Goldstein, H., Browne, W., \& Rasbash, J. (2002). Multilevel modelling of medical data. Statistics in medicine, 21(21), 32913315. doi: $10.1002 / \mathrm{sim} .1264$

[15] Jaber, M. A., AIQahtani, F., Bishawi, K., \& Kuriadom, S. T. (2021). Patterns of maxillofacial injuries in the Middle East and North Africa: a systematic review. International dental journal, 1-9. doi: 10.1111/idj.12587

[16] Khan, Z. U., Al-Asiri, K. M., \& Iqbal, J. (2010). Injury patterns from road traffic accidents. Pakistan Journal of Medical Sciences, 26(2), 394-397.

[17] Khudyk, А. К. (2020). Аналіз особливостей травматичних уражень середньої зони обличчя [Analysis of the features of traumatic lesions of the middle face zone]. Український журнал медицини, біології та спорту - Ukrainian Journal of Medicine, Biology and Sports, 5(27), 242-247.

[18] Kraus, D. (2014). Consolidated data analysis and presentation using an open-source add-in for the Microsoft Excel ${ }^{\circledR}$ spreadsheet software. Medical Writing, 23(1), 25-28. doi: 10.1179/2047480613Z.000000000181

[19] Pietzka, S., Kammerer, P. W., Pietzka, S., Schramm, A., Lampl, L., Lefering, R., ... \& Kulla, M. (2020). Maxillofacial injuries in severely injured patients after road traffic accidents - a retrospective evaluation of the TraumaRegister DGU® 19932014. Clinical oral investigations, 24(1), 503-513. doi: 10.1007/ s00784-019-03024-6

[20] Ramalingam, S. (2015). Role of maxillofacial trauma scoring systems in determining the economic burden to maxillofacial trauma patients in India. Journal of international oral health: JIOH, 7(4), 38. PMID: 25954069

[21] Ruslin, M., Brucoli, M., Boffano, P., Benech, A., Dediol, E., Uglešič, V., ... \& Forouzanfar, T. (2019). Motor vehicle accidents-related maxillofacial injuries: a multicentre and prospective study. Oral surgery, oral medicine, oral pathology and oral radiology, 128(3), 199-204. doi: 10.1016/ j.0000.2018.12.009

[22] Rybachuk, A. V. Mamonov, R. O., \& Malanchuk, V. O. (2016). Епідеміологія травматичних переломів нижньої щелепи в період з 2005 по 2014 р. за матеріалами клініки кафедри [Epidemiology of traumatic fractures of the mandible in the period from 2005 to 2014 according to the clinic of the department]. Харківська хірургічна школа - Kharkiv Surgical School, (1), 117-122.

[23] Sadeghi, N., Parandoosh, P., \& Kalantar Motamedi, M. H. (2019). Patterns of maxillofacial fractures: a systematic review. Trauma Monthly, 24(4), 1-6. doi: 10.5812/TRAUMAMON.87169

[24] Sadeghi-Bazargani, H., Ayubi, E., Azami-Aghdash, S., Abedi, L., Zemestani, A., Amanati, L., ... \& Safiri, S. (2016). Epidemiological patterns of road traffic crashes during the last two decades in Iran: a review of the literature from 1996 to 2014. Archives of trauma research, 5(3), e32985. doi: 10.5812/atr.32985

[25] Sani, M. K., Zadeh, S. M. M., Ezzati, A., \& Ezzati, A. (2020). Determine the proportion of maxillofacial trauma resulting from different etiologies among children: systematic review and meta-analysis. JCR, 7(15), 82-92. doi: 10.31838/jcr.07.15.13

[26] Saperi, B. S., Ramli, R., Ahmed, Z., Nur, A. M., Ibrahim, M. I., Rashdi, M. F., ... \& Mohamed, N. (2017). Cost analysis of facial injury treatment in two university hospitals in Malaysia: a prospective study. ClinicoEconomics and outcomes research: CEOR, 9, 107-113. doi: 10.2147/CEOR.S119910

[27] Siregar, D. F., Buchari, F. B., Tarigan, U. A., \& Lelo, A. (2019). Correlation of facial injury severity scale (FISS) with length of stay, the need for surgery and the involvement of other specialists in maxillofacial trauma patients at $\mathrm{H}$. Adam Malik General Hospital Medan. Global journal for research analysis, 8(11), 8-10. doi: 10.36106/gjra/9407348

[28] Suwal, R. (2018). Analysis of Mid-face Fractures using MFISS and FISS Scoring Systems. J Nepal Dent Assoc, 18(1), 21-29.

[29] Tkachenko, P. I., \& Idashkina, N. Н. (2011). Недоліки в діагностиці та лікуванні переломів нижньої щелепи в межах зубного ряду дротяними шинами [Disadvantages in the diagnosis and treatment of mandibular fractures within the dentition with wire splints]. Мир медицины и биологии World of Medicine and Biology, 7(2), 158-161.

[30] Wusiman, P., Maimaitituerxun, B., Saimaiti, A., \& Moming, A. (2020). Epidemiology and pattern of oral and maxillofacial trauma. Journal of Craniofacial Surgery, 31(5), e517-e520. doi: 10.1097/SCS.0000000000006719

[31] Zhang, J., Zhang, Y., El-Maaytah, M., Ma, L., Liu, L., \& Zhou, L. D. (2006). Maxillofacial Injury Severity Score: proposal of a new scoring system. International journal of oral and maxillofacial surgery, 35(2), 109-114. doi: 10.1016/ j.ijom.2005.06.019 